\title{
Chapter 22 \\ Effect of Macrophage Colony-Stimulating Factor Receptor c-Fms Antibody on Lipopolysaccharide-Induced Pathological Osteoclastogenesis and Bone Resorption
}

\author{
Keisuke Kimura, Hideki Kitaura, Masahiko Ishida, Zaki Hakami, \\ Jafari Saeed, Haruki Sugisawa, and Teruko Takano-Yamamoto
}

\begin{abstract}
Lipopolysaccharide (LPS) is a major component of Gram-negative bacteria cell walls and is a well-known potent inducer of inflammation and pathogens of inflammatory bone loss. Formation of osteoclasts is highly dependent on the presence of macrophage colony-stimulating factor (M-CSF) and receptor activator of nuclear factor kappa-B ligand (RANKL). Recent reports indicate that biological preparations, including anti-RANKL antibody and anti-tumor necrosis factor- $\alpha$ antibody, positively influence rheumatoid arthritis and osteoporosis. In this study, we aimed to investigate whether the M-CSF receptor c-Fms antibody would inhibit the formation of osteoclasts. C57BL6/J mice were injected with either LPS, LPS and anti-c-Fms antibody, anti-c-Fms antibody, or PBS into the supracalvariae. Animals were sacrificed and calvariae fixation and demineralization were performed. Histological sections of calvariae were stained for tartrate-resistant acid phosphatase (TRAP). In mice administered with both LPS and the anti-cFms antibody, osteoclast numbers were lower than those in mice administered with LPS alone. Moreover, levels of TRACP-5b, a bone resorption marker in mice serum, were lower in mice administered with both LPS and the anti-c-Fms antibody than in mice administered with LPS alone. These results suggest that M-CSF and its receptor are potential therapeutic targets in LPS-induced osteoclastogenesis, and that the anti-c-Fms antibody might be useful for inhibition of inflammation-induced bone erosion. In this study, we describe and discuss the effect the anti-c-Fms antibody has on pathological osteoclastogenesis and bone resorption.
\end{abstract}

Keywords LPS $\bullet$ M-CSF • Osteoclast

K. Kimura $\bullet$ H. Kitaura $\bullet$ M. Ishida $\bullet$ Z. Hakami $\bullet$ J. Saeed $\bullet$ H. Sugisawa

T. Takano-Yamamoto $(\bowtie)$

Division of Orthodontics and Dentofacial Orthopedics, Department of Translational Medicine,

Tohoku University Graduate School of Dentistry, 4-1 Seiryo-machi, Aoba-ku,

Sendai 980-8575, Japan

e-mail: t-yamamo@m.tohoku.ac.jp 


\subsection{Biological Effect of Macrophage Colony-Stimulating Factor (M-CSF)}

Macrophage colony-stimulating factor (M-CSF) is a known hematopoietic growth factor and regulator of key functions of macrophages and monocytes. M-CSF mediates the survival and proliferation of precursors of the monocyte and macrophage lineage and their differentiation into mature phagocytes [1, 2]. Macrophages, in relation to the immune response, exist as phagocytes and antigen-presenting cells $[3,4]$. Furthermore, the activity of macrophages is associated with the regulation of many biological processes and is dependent on the actual macrophage phenotype induced under various inflammatory conditions [1]. Macrophages play an important role in homeostasis, autoimmunization, and first defense during infection. Macrophages react to tissue damage through non-specific activation followed by overproduction of proinflammatory factors within the pathological condition [5]. Furthermore, allergen or self-antigen presentation on macrophages induces a chronic inflammatory response and stultification of immunity. Primitive macrophages develop from hematopoietic cells and then differentiate into fetal macrophages. Monocytes are also differentiated from hematopoietic cells in the bone marrow and fetal hematopoietic organs. Macrophages contribute as effectors of metabolism and the host defense. When macrophages are depleted, bilirubin production and host resistance to infection are severely reduced. Macrophage growth factors induce macrophage differentiation and function. M-CSF-deficient mice are deficient in monocytes, tissue macrophages, and osteoclasts and show osteopetrotic phenotypes [6]. It has been reported that macrophages incorporate chemically modified, low-density lipoprotein (LDL) and differentiate into foam cells in the arterial wall [7]. When oxidized LDL binds to liver X receptor $\alpha$, this upregulates expression of its target genes and acts to remove cholesterol from macrophages. Inflammatory signals downregulate the expression of liver $\mathrm{X}$ receptor $\alpha$ and enhance lipid accumulation [7]. Therefore, macrophages play a pivotal role in metabolism and host defense. Thus, the macrophage/monocyte growth factor, $\mathrm{M}-\mathrm{CSF}$, plays an important role in these events.

\subsection{The Role of M-CSF in Osteoclast Formation and Bone Remodeling}

Many cytokine contribute to osteoclast formation [8-12]. M-CSF is one of the essential cytokine for osteoclastgenesis. M-CSF plays an important role in bone remodeling and mediates osteoclast differentiation and the survival and proliferation of osteoclast precursors [13, 14]. The osteoclast, which is a unique bone resorptive cell, is a member of the macrophage family. Osteoclastogenesis is dependent on M-CSF and receptor activator of nuclear factor kappa-B ligand (RANKL) [15]. Osteoclasts play a role in bone resorption and maintain bone 
homeostasis. This event was confirmed by the observation that osteopetrotic (op/op) mutant mice, deficient in expression of M-CSF, show an osteopetrotic phenotype [14]. Additionally, administration of soluble M-CSF to op/op mice rescues their osteoclast formation potential and occurrence of osteoporosis [6]. The functional relationship between M-CSF and its receptor is established in mice lacking c-fms, which display the same phenotype as the op/op mouse. These mice have decreased tissue macrophages and severe osteopetrosis owing to a lack of osteoclasts [16-19]. Mice homozygous for the osteopetrosis mutation are characterized by defective differentiation of osteoclasts, monocytes, and tissue macrophages, owing to the lack of M-CSF activity. It has been reported that the bone marrow cavities were filled with spongious bone in young op/op mice. Conversely, the bone marrow cavities were reconstructed and marrow hematopoiesis was increased in old op/op mice [7]. Osteoclast and bone marrow macrophage cell numbers were also increased in old op/op mice. However, many of the osteoclasts were mononuclear not multinuclear cells and showed insufficiently developed ruffled borders. Furthermore, in old op/op mice, lysosomes of bone marrow macrophages were laden with abundant crystalloid materials, which was not observed in young op/op mice. Although the number of Kupffer cells in the liver was not increased in the old op/op mice, cell ultrastructural maturation was absent and some crystalloid structures were observed [7]. M-CSF administration to old op/op mice increased the number of Kupffer cells and induced lysosome formation in the Kupffer cells. Furthermore, M-CSF administration reduced crystalloid structures in the lysosomes of the Kupffer cells and permitted development of atypical ruffled border in the osteoclasts [7]. These results suggest that the M-CSF-independent mechanisms for macrophage and osteoclast development in old op/op mice are restricted to the bone marrow. M-CSF plays important roles in the differentiation of macrophages and osteoclasts and the production and function of lysosomes. Binding of M-CSF to c-Fms activates the receptor tyrosine kinase and induces autophosphorylation of the dimer on selected tyrosine residues. The M-CSF/c-fms signaling pathway leads to activated phosphorylation of $\mathrm{Pl} 3 \mathrm{~K}$, cSrc, and ERK, which are critical for proliferation and survival of osteoclast precursors [20, 21].

Rheumatoid arthritis (RA) is a highly complex condition, the pathogenesis of which results from a host of cytokines produced by a variety of cells. While RANKL and interleukin (IL)-1 are important participants in the development of focal bone erosions, which eventuate in joint collapse, tumor necrosis factor (TNF)$\alpha$ is the principal and rate-limiting culprit, whose blockade dampens both the inflammatory and osteoclastogenic components of the disease [22]. However, blockade of TNF- $\alpha$ alone is insufficient to optimize arrest of inflammatory joint disease, as coordinated treatment with IL-1 receptor antagonist (IL-1Ra) is more effective [23]. Added to the potential complications attending TNF- $\alpha$ inhibition, these observations underscore the importance of identifying new therapeutic candidates in this disease, a goal which can be achieved only by gaining insight into the means by which TNF- $\alpha$ impacts target cells.

While M-CSF is constitutively produced by a range of mesenchymal cells, its regulated secretion has pathological consequences in the context of the osteoclast. 
Thus, absence of estrogen, the cause of postmenopausal osteoporosis, is because of enhanced bone resorption caused, at least in part, by increased production of M-CSF by bone marrow stromal cells [24]. Similarly, the enhanced osteoclastogenesis observed following deletion of the $\beta 3$ integrin gene is due to stimulated M-CSF expression [25]. Regarding inflammatory osteolysis, the cytokine is increased in the serum of patients with RA [26] and those with severe ankylosing spondylitis [27], as well as in the synovial fluid around loose joint prostheses [28].

\subsection{Biological Antibody Therapy for Bone Disease}

Recently, biological preparations, including anti-RANKL antibody and anti-TNF- $\alpha$ antibody, have been reported to positively influence RA, osteoporosis, and cancer bone metastasis [29]. These antibodies act as decoys to prevent receptor binding and therefore inhibit osteoclastogenesis. Denosumab, an anti-bone resorptive drug, is a complete human-type monoclonal antibody for RANKL [30, 31]. Denosumab has been shown to elicit an inhibitory effect on bone resorption in patients with osteoporosis and RA. However, in patients with massive renal dysfunction, denosumab administration increases the risk of hypocalcemia. Denosumab binds to a specific loop structure on the RANKL molecule and inhibits its interaction with its receptor, RANK [32]. When labeled with radioactivity, denosumab was detected in the lymph nodes and spleen after subcutaneous administration, indicating positive RANKL binding of the drug within those tissues. Therefore, researchers and clinicians are interested in the inhibitory effects of denosumab on bone resorption, as well as its mode of action. Biological therapy by blocking the TNF- $\alpha$ receptor is an efficacious RA treatment. TNF- $\alpha$ is produced primarily by activated macrophages and induces osteoclast formation via activated phosphorylation of P38, JNK, and AP-1. This cytokine likely plays a key role in RA pathogenesis [11, 32, 33]. Infliximab is a chimeric monoclonal IgG1 antibody against TNF- $\alpha$ [34]. It neutralizes TNF- $\alpha$ biological activity and inhibits bone distraction [35]. However, one side-effect of infliximab includes immunodeficiency, therefore it needs to be use cautiously.

\subsection{The Inhibitory Effect of the Anti-c-Fms Antibody in Pathological Osteoclast Formation and Bone Resorption}

In this review, we describe and discuss the effect of the anti-c-Fms antibody on the pathology of osteoclastogenesis and bone resorption. M-CSF is produced by mesenchymal cells and its regulated secretion has physiological and pathological consequences for osteoclasts. M-CSF promotes the survival and longevity of 
osteoclast precursors and organizes osteoclast cytoskeletons [15]. The absence of estrogen in post-menopausal osteoporosis is because of enhanced bone resorption caused by increased production of M-CSF by marrow stromal cells [24]. The level of M-CSF is increased in the serum of patients with RA who have severe ankylosing spondylitis [36] and in the synovial fluid around loose joint prostheses [28]. These observations suggest that stromal cell-produced M-CSF may be an important mediator of inflammation-induced osteoclastogenesis. Indeed, it has been reported that TNF- $\alpha$ induces M-CSF gene expression in stromal cells and increases the number of osteoclast precursors in vivo [37]. Stromal cell-produced M-CSF may be an important mediator of TNF-stimulated osteoclastogenesis. In fact, TNF- $\alpha$ has been shown to induce M-CSF gene expression in vivo and only in the presence of stromal cell-residing TNFRs. The capacity of TNF- $\alpha$ to increase osteoclast precursor numbers in vivo, corresponds with the pro-proliferative and pro-survival properties of abundant levels of M-CSF. The fact that TNF- $\alpha$ enhances osteoclast precursor numbers in the presence of only constitutive levels of M-CSF, suggests that, like its interaction with RANKL, this inflammatory cytokine synergizes with M-CSF to enhance osteoclast precursor numbers. In fact, mice treated with carrier or anti-c-Fms mAb developed equivalent periarticular inflammation, while those receiving the antibody were completely free of pathological osteoclastogenesis and bone resorption. This observation reflects, to a substantial degree, the arrest of TNF signaling, as similar results were obtained in TNF- $\alpha$-injected mice also receiving the anti-c-Fms antibody.

Mechanical force loading exerts important effects on the skeleton by controlling bone mass and strength. Orthodontic tooth movement is a good model for exploring the mechanism of mechanical loading-induced bone remodeling. In a mouse model of orthodontic tooth movement, TNF- $\alpha$ was expressed and osteoclasts appeared on the compressed side of the periodontal ligament. In TNF-receptor-deficient mice, there was less tooth movement and osteoclast numbers were lower than in wild-type mice. These results suggest that osteoclast formation and bone resorption are caused by mechanical loading-induced TNF- $\alpha$ secretion and that TNF- $\alpha$ is concerned with orthodontic tooth movement [38]. However, the relationship between orthodontic movement and TNF- $\alpha$ is not fully understood as yet. Blocking M-CSF with an anti-c-Fms antibody was shown to inhibit osteoclast formation and tooth movement [39]. These results suggest that control of M-CSF could regulate osteoclast formation and subsequent orthodontic tooth movement. Root resorption often occurs following orthodontic treatment and is a serious problem for the orthodontist and patient. During one study, the anti-c-Fms antibody was locally injected adjacent to the first molar every other day during the experimental period. The anti-c-Fms antibody was found to inhibit odontoclastogenesis and root resorption during orthodontic tooth movement [39].

M-CSF and/or its receptor is therefore a potential therapeutic target in mechanical stress-induced odontoclastogenesis, and injection of the anti-c-Fms antibody might be useful for inhibition of mechanical stress-induced root resorption during orthodontic tooth movement. 
Bacterial infection and lipopolysaccharide (LPS) are reported to induce osteoclast formation and inflammatory bone loss, as seen in periodontal diseases [40, 41]. LPS is major component of bacteria and is reported to be an inducer of inflammation and pathological bone resorption. We therefore, aimed to examine the effect of LPS on osteoclastogenesis and the anti-c-Fms antibody. We assumed that the M-CSF receptor c-Fms antibody would inhibit LPS-induced osteoclast formation. In our study, we showed that LPS induced M-CSF expression in vivo. The anti-c-Fms antibody has been previously reported to inhibit RANKL-induced osteoclastogenesis in vitro and completely block pathological osteoclastogenesis and bone resorption, induced by inflammatory arthritis and direct injection of TNF- $\alpha$ [42]. In the present study, we administered LPS with and without the antic-Fms antibody into mouse supracalvariae to analyze the effect of the anti-c-Fms antibody on LPS-induced osteoclastogenesis in vivo. In the LPS-administered group, increased numbers of osteoclasts were observed. In comparison, the number of osteoclasts was significantly reduced in the group administered with both LPS and the anti-c-Fms antibody, which was dependent on the concentration of the antic-Fms antibody. Levels of both cathepsin K and tartrate-resistant acid phosphatase mRNAs were also significantly lower in the group administered with both LPS and the anti-c-Fms antibody compared with the LPS-administered group. These results showed that anti-c-Fms antibody inhibited LPS-induced osteoclast formation [43]. To examine whether the anti-c-Fms antibody inhibited LPS-induced osteolysis, we used three-dimensional reconstruction images of calvariae obtained by microfocal computed tomography $(\mu-\mathrm{CT})$. Many radiolucent spots on calvariae were observed in the $\mu$-CT images in the LPS-administered group but not in the group administered both LPS and the anti-c-Fms antibody. Furthermore, the level of TRACP-5b, a bone resorption marker, was lower in the serum of the group administered both LPS and the anti-c-Fms antibody compared with the LPS-administered group. The results suggest that the anti-c-Fms antibody can inhibit LPS-induced osteolysis by inhibition of osteoclast formation [43]. Our results showed that osteoclasts were induced in calvariae in the presence of LPS. Several previous studies have indicated that LPS induces the expression of inflammatory cytokines, such as TNF-a, IL-1, and IL-6, in vitro and in vivo. Furthermore, it has been reported that TNF- $\alpha$ induces M-CSF expression in stromal cells in vivo $[42,44]$. In our study, we found that LPS induced M-CSF expression in vivo. It has been reported that M-CSF induces RANK expression by bone marrow macrophages in vitro [42]. We therefore investigated whether LPS-induced RANK expression in vivo was dependent on M-CSF. We found LPS-induced RANK gene and protein expression were inhibited by the anti-c-Fms antibody in vivo [43]. These results suggest that RANK expression induced by LPS in vivo might be dependent on LPS-induced M-CSF levels. Taken together, the inhibition of LPS-induced RANK expression might be one factor behind the inhibitory effect of the anti-c-Fms antibody on osteoclastogenesis. 


\subsection{Conclusions}

M-CSF has an important role within the immune system and bone remodeling, representing one of many cytokines involved in the pathogenesis of inflammatory osteolysis. Although M-CSF-signaling is initiated at the induction of the arthritic process, the profundity of its effect on osteoclasts, as compared with macrophages, enhances its therapeutic appeal. The potential of M-CSF inhibition as a means of treating RA is underscored by the development of c-Fms-selective small molecules [45] and the capacity of the tyrosine kinase inhibitor drug, imatinib, to target the receptor [46]. Given the significant complications encountered with other forms of anti-cytokine therapy, however, the therapeutic targeting of M-CSF must be approached with caution [47]. M-CSF and/or its receptor are potential therapeutic targets for the treatment of bacterial infection-induced osteolysis caused by LPS. The injection of an anti-c-Fms antibody might be useful for the inhibition of pathological bone resorption during bacterial infection.

Taken together, these data indicate that M-CSF is a key cytokine that plays a central role in inflammatory osteolysis and might be a therapeutic target. However, M-CSF accelerates formation of osteoclasts by increasing their precursor pool, the majority of which fail to become bone resorptive polykaryons, but host defense mononuclear phagocytes. Thus, the coincident immunosuppressive effect of inhibiting macrophage proliferation and survival as a means of arresting inflammatory periarticular erosion, is a potential limitation of M-CSF blockade. Further studies are necessary to clarify this aspect.

Open Access This chapter is distributed under the terms of the Creative Commons Attribution Noncommercial License, which permits any noncommercial use, distribution, and reproduction in any medium, provided the original author(s) and source are credited.

\section{References}

1. Li Y, Chen Q, Zheng D, Yin L, Chionh YH, Wong LH, et al. Induction of functional human macrophages from bone marrow promonocytes by M-CSF in humanized mice. J Immunol. 2013;191(6):3192-9.

2. Cecchini MG, Dominguez MG, Mocci S, Wetterwald A, Felix R, Fleisch H, et al. Role of colony stimulating factor- 1 in the establishment and regulation of tissue macrophages during postnatal development of the mouse. Development. 1994;120(6):1357-72.

3. Calderon B, Carrero JA, Unanue ER. The central role of antigen presentation in islets of Langerhans in autoimmune diabetes. Curr Opin Immunol. 2014;26:32-40.

4. D'Souza AJ, Desai SD, Rudner XL, Kelly MN, Ruan S, Shellito JE. Suppression of the macrophage proteasome by ethanol impairs MHC class I antigen processing and presentation. PLoS One. 2013;8(2):e56890.

5. Nazimek K, Bryniarski K. The biological activity of macrophages in health and disease. Postepy Hig Med Dosw (Online). 2012;66:507-20.

6. Abboud SL, Woodruff K, Liu C, Shen V, Ghosh-Choudhury N. Rescue of the osteopetrotic defect in op/op mice by osteoblast-specific targeting of soluble colony-stimulating factor-1. Endocrinology. 2002;143(5):1942-9. 
7. Naito M. Macrophage differentiation and function in health and disease. Pathol Int. 2008;58 (3): $143-55$.

8. Kobayashi K, Takahashi N, Jimi E, Udagawa N, Takami M, Kotake S, et al. Tumor necrosis factor alpha stimulates osteoclast differentiation by a mechanism independent of the ODF/ RANKL-RANK interaction. J Exp Med. 2000;191:275-86.

9. Kodama H, Nose M, Niida S, Yamasaki A. Essential role of macrophage colony-stimulating factor in the osteoclast differentiation supported by stromal cells. J Exp Med. 1991;173 (5):1291-4.

10. Lacey DL, Timms E, Tan HL, Kelley MJ, Dunstan CR, Burgess T, et al. Osteoprotegerin ligand is a cytokine that regulates osteoclast differentiation and activation. Cell. 1998;93 (2):165-76.

11. Redlich K, Hayer S, Ricci R, David JP, Tohidast-Akrad M, Kollias G, et al. Osteoclasts are essential for TNF-alpha-mediated joint destruction. J Clin Invest. 2002;110:1419-27.

12. Ross FP. M-CSF, c-Fms, and signaling in osteoclasts and their precursors. Ann N Y Acad Sci. 2006;1068:110-6.

13. Glantschnig H, Fisher JE, Wesolowski G, Rodan GA, Reszka AA. M-CSF, TNFalpha and RANK ligand promote osteoclast survival by signaling through mTOR/S6 kinase. Cell Death Differ. 2003;10(10):1165-77.

14. Yoshida H, Hayashi S, Kunisada T, Ogawa M, Nishikawa S, Okamura H, et al. The murine mutation osteopetrosis is in the coding region of the macrophage colony stimulating factor gene. Nature. 1990;345:442-4.

15. Teitelbaum SL. Bone resorption by osteoclasts. Science. 2000;289(5484):1504-8.

16. Dai XM, Zong XY, Sylvestre V, Stanley ER. Incomplete restoration of colony-stimulating factor 1 (CSF-1) function in CSF-1-deficient Csf1op/Csf1op mice by transgenic expression of cell surface CSF-1. Blood. 2004;103(3):1114-23.

17. Wiktor-Jedrzejczak W, Bartocci A, Ferrante Jr AW, Ahmed-Ansari A, Sell KW, Pollard JW, et al. Total absence of colony-stimulating factor 1 in the macrophagedeficient osteopetrotic (op/op) mouse. Proc Natl Acad Sci U S A. 1990;87(12):4828-32.

18. Wiktor-Jedrzejczak W, Ratajczak MZ, Ptasznik A, Sell KW, Ahmed-Ansari A, Ostertag W. CSF-1 deficiency in the op/op mouse has differential effects on macrophage populations and differentiation stages. Exp Hematol. 1992;20(8):1004-10.

19. Naito M, Hayashi S, Yoshida H, Nishikawa S, Shultz LD, Takahashi K. Abnormal differentiation of tissue macrophage populations in 'osteopetrosis' (op) mice defective in the production of macrophage colony-stimulating factor. Am J Pathol. 1991;139(3):657-67.

20. Long CL, Humphrey MB. Osteoimmunology: the expanding role of immunoreceptors in osteoclasts and bone remodeling. Bonekey Rep. 2012;1:59.

21. Bruzzaniti A, Baron R. Molecular regulation of osteoclast activity. Rev Endocr Metab Disord. 2006; 7(1-2):123-39.

22. Smolen JS, Steiner G. Therapeutic strategies for rheumatoid arthritis. Nat Rev Drug Discov. 2003;2(6):473-88.

23. Zwerina J, Hayer S, Tohidast-Akrad M, Bergmeister H, Redlich K, Feige U, et al. Single and combined inhibition of tumor necrosis factor, interleukin-1, and RANKL pathways in tumor necrosis factor-induced arthritis: effects on synovial inflammation, bone erosion, and cartilage destruction. Arthritis Rheum. 2004;50(1):277-90.

24. Srivastava S, Weitzmann MN, Kimble RB, Rizzo M, Zahner M, Milbrandt J, et al. Estrogen blocks M-CSF gene expression and osteoclast formation by regulating phosphorylation of Egr-1 and its interaction with Sp-1. J Clin Invest. 1998;102(10):1850-9.

25. Faccio R, Takeshita S, Zallone A, Ross FP, Teitelbaum SL. c-Fms and the alphavbeta3 integrin collaborate during osteoclast differentiation. J Clin Invest. 2003;111(5):749-58.

26. Kawaji H, Yokomura K, Kikuchi K, Somoto Y, Shirai Y. Macrophage colony-stimulating factor in patients with rheumatoid arthritis. Nihon Ika Daigaku Zasshi. 1995;62(3):260-70.

27. Yang C, Gu J, Rihl M, Baeten D, Huang F, Zhao M, et al. Serum levels of matrix metalloproteinase 3 and macrophage colony-stimulating factor 1 correlate with disease activity in ankylosing spondylitis. Arthritis Rheum. 2004;51(5):691-9. 
28. Takei I, Takagi M, Ida H, Ogino T, Santavirta S, Konttinen YT. High macrophage-colony stimulating factor levels in synovial fluid of loose artificial hip joints. J Rheumatol. 2000;27 (4):894-9.

29. Yasuda H. RANKL, a necessary chance for clinical application to osteoporosis and cancerrelated bone diseases. World J Orthop. 2013;4(4):207-17.

30. Schwarz EM, Ritchlin CT. Clinical development of anti-RANKL therapy. Arthritis Res Ther. 2007;9 Suppl 1:S7.

31. Lipton A, Goessl C. Clinical development of anti-RANKL therapies for treatment and prevention of bone metastasis. Bone. 2011;48(1):96-9.

32. Miyazaki T, Tokimura F, Tanaka S. A review of denosumab for the treatment of osteoporosis. Patient Prefer Adherence. 2014;8:463-71.

33. Feldmann M, Maini RN. Anti-TNF alpha therapy of rheumatoid arthritis: what have we learned? Annu Rev Immunol. 2001;19:163-96.

34. Voloshyna I, Seshadri S, Anwar K, Littlefield MJ, Belilos E, Carsons SE, et al. Infliximab reverses suppression of cholesterol efflux proteins by TNF- $\alpha$ : a possible mechanism for modulation of atherogenesis. Biomed Res Int. 2014;2014:312647.

35. Feldman M, Taylor P, Paleolog E, Brennan FM, Maini RN. Anti-TNF $\alpha$ therapy is useful in rheumatoid arthritis and Crohn's disease: analysis of the mechanism of action predicts utility in other diseases. Transplant Proc. 1998;30(8):4126-7.

36. Azuma Y, Kaji K, Katogi R, Takeshita S, Kudo A. Tumor necrosis factor-alpha induces differentiation of and bone resorption by osteoclasts. J Biol Chem. 2000;275(7):4858-64.

37. Yang PT, Kasai H, Xiao WG, Zhao LJ, He LM, Yamashita A, et al. Increased expression of macrophage colony-stimulating factor in ankylosing spondylitis and rheumatoid arthritis. Ann Rheum Dis. 2006;65(12):1671-2.

38. Kitaura H, Zhou P, Kim HJ, Novack DV, Ross FP, Teitelbaum SL. M-CSF mediates TNF-induced inflammatory osteolysis. J Clin Invest. 2005;115(12):3418-27.

39. Yoshimatsu M, Shibata Y, Kitaura H, Chang X, Moriishi T, Hashimoto F, et al. Experimental model of tooth movement by orthodontic force in mice and its application to tumor necrosis factor receptor-deficient mice. J Bone Miner Metab. 2006;24(1):20-7.

40. Kitaura H, Yoshimatsu M, Fujimura Y, Eguchi T, Kohara H, Yamaguchi A, et al. An anti-cFms antibody inhibits orthodontic tooth movement. J Dent Res. 2008;87(4):396-400.

41. Slots J, Genco RJ. Black-pigmented Bacteroides species, Capnocytophaga species, and Actinobacillus actinomycetemcomitans in human periodontal disease: virulence factors in colonization, survival, and tissue destruction. J Dent Res. 1984;63(3):412-21.

42. Abu-Amer Y, Ross FP, Edwards J, Teitilbaum SL. Lipopolysaccharide-stimulated osteoclastogenesis is mediated by tumor necrosis factor via its P55 receptor. J Clin Invest. 1997;100 (6): $1557-65$.

43. Kimura K, Kitaura H, Fujii T, Hakami ZW, Takano-Yamamoto T. Anti-c-Fms antibody inhibits lipopolysaccharide-induced osteoclastogenesis in vivo. FEMS Immunol Med Microbiol. 2012;64(2):219-27.

44. Kitaura H, Sands MS, Aya K, Zhou P, Hirayama T, Uthgenannt B, et al. Marrow stromal cells and osteoclast precursors differentially contribute to TNF-alpha-induced osteoclastogenesis in vivo. J Immunol. 2004;173(8):4838-46.

45. Murray LJ, Abrams TJ, Long KR, Ngai TJ, Olson LM, Hong W, et al. SU11248 inhibits tumor growth and CSF-1R-dependent osteolysis in an experimental breast cancer bone metastasis model. Clin Exp Metastasis. 2003;20(8):757-66.

46. Dewar A, Zannettino AC, Hughes TP, Lyons AB. Inhibition of c-fms by imatinib: expanding the spectrum of treatment. Cell Cycle. 2005;4(7):851-3.

47. Genovese MC, Cohen S, Moreland L, Lium D, Robbins S, Newmark R, et al. Combination therapy with etanercept and anakinra in the treatment of patients with rheumatoid arthritis who have been treated unsuccessfully with methotrexate. Arthritis Rheum. 2004;50(5):1412-9. 